\title{
Mixed-function oxidases and esterases associated with cross-resistance between DDT and lambda-cyhalothrin in Anopheles darlingi Root 1926 populations from Colombia
}

\author{
Idalyd Fonseca-González¹+, Martha L Quiñones², Janet McAllister³, William G Brogdon ${ }^{4}$
}

\begin{abstract}
'Programa de Estudio y Control de Enfermedades Tropicales and Grupo de Chagas, Lab. 620, Sede de Investigación Universitaria, Instituto de Biología, Facultad de Ciencias Exactas y Naturales, Universidad de Antioquia, Calle 62 52-59, Medellín, Colombia ²Departamento de Salud Pública, Facultad de Medicina, Universidad Nacional de Colombia, Bogotá, Colombia ${ }^{3}$ Centers for Disease Control and Prevention, Arboviral Diseases Branch, Fort Collins, Colorado, USA ${ }^{4}$ Centers for Disease Control and Prevention, Entomology Branch, Atlanta, USA
\end{abstract}

In order to establish the insecticide susceptibility status for Anopheles darlingi in Colombia, and as part of the National Network on Insecticide Resistance Surveillance, five populations of insects from three Colombian states were evaluated. Standardised WHO and CDC bottle bioassays, in addition to microplate biochemical assays, were conducted. Populations with mortality rates below $80 \%$ in the bioassays were considered resistant. All field populations were susceptible to deltamethrin, permethrin, malathion and fenitrothion. Resistance to lambda-cyhalothrin and DDT was detected in the Amé-Beté population using both bioassay methods with mortality rates of 65-75\%. Enzyme levels related to insecticide resistance, including mixed function oxidases (MFO), non-specific esterases (NSE), glutathione S-transferases and modified acetylcholinesterase were evaluated in all populations and compared with a susceptible natural strain. Only mosquitoes from Amé-Beté presented significantly increased levels of both MFO and NSE, consistent with the low mortalities found in this population. The continued use of lambdacyhalothrin for An. darlingi control in this locality has resulted in a natural resistance to this insecticide. In addition, DDT resistance is still present in this population, although this insecticide has not been used in Colombia since 1992. Increased metabolism through MFO and NSE may be involved in cross-resistance between lambdacyhalothrin and DDT, although $\mathrm{kdr}$-type nerve insensitivity cannot be discarded as a possible hypothesis. Additional research, including development of a $\mathrm{kdr}$ specific assay for An. darlingi should be conducted in future studies. Our data demonstrates the urgent need to develop local insecticide resistance management and surveillance programs throughout Colombia.

Key words: insecticide resistance - bioassays - oxidases - esterases - Anopheles darlingi - Colombia

Malaria is one of the major causes of morbidity and mortality worldwide. Nineteen countries in Latin America report active transmission of the disease, with one million clinical episodes annually. In addition, almost 250 million people are currently living in areas of risk for malarial infection (PAHO 2005). After Brazil, Colombia is the country with the highest index of malaria transmission in the Americas (WHO 2005a). Of all the cases that occurred during $2007,27.5 \%$ were caused by Plasmodium falciparum. The zones of greatest transmission are located in the region of Bajo Cauca, Pacific Coast, the Valley of Sinú River and the region of Urabá (WHO 2005a, Sivigila 2007). In these areas, epidemic outbreaks are closely related with ecological imbalances and population displacement, resulted from the social situation in the country (WHO 2005b).

\footnotetext{
Financial support: Instituto Colombiano para el Desarrollo de la Ciencia y la Tecnología Francisco José de Caldas, COLCIENCIAS (grant 22290416444)

+ Corresponding author: idalyd.fonseca@siu.udea.edu.co

Received 20 May 2008

Accepted 23 December 2008
}

Although early diagnosis and treatment contributes to the prevention of malaria, control of vectors continues to be the most effective way of interrupting transmission in endemic areas. This measure of control is considered to be one of the four basic technical elements of the global strategy for malaria control (WHO 1993). Although vector control methods vary considerably in their applicability, costs and the reproducibility of results, there is a worldwide consensus for the use of indoor residual spraying (IRS) and insecticide treated nets (ITNs) with residual insecticides as major measures for the prevention of malaria. Both methods are effective in reducing the transmission of this disease through reducing the longevity of the vectors and decreasing human-vector contact (Lengeler \& Sharp 2003).

There are 45 Anopheles species documented in Colombia, but only seven are considered to be malaria vectors. Among the seven vectors, Anopheles darlingi Root 1926 is recognised as the major vector in the regions of Bajo Cauca, Middle Atrato, Amazon and Eastern Colombia (Olano et al. 2001). This species is very effective as a malaria vector due to its highly anthropophilic behaviour and susceptibility to infection with both $P$. falciparum and Plasmodium vivax (Zimmerman 1992). The endophilic character of this species has allowed it to be controlled through IRS. After the suspension of DDT 
use in Colombia, the organophosphate fenitrothion and recently the pyrethroids lambda-cyhalothrin and deltamethrin are used, mainly as water-soluble powders and emulsified concentrate formulations. Some municipalities also carry out ULV space applications using lambda-cyhalothrin, deltamethrin and pirimiphos methyl. In addition, the local authorities in charge of vector control periodically distribute ITNs impregnated with lambdacyhalothrin, deltamethrin or permethrin to the communities in endemic areas (JD Palacios \& W Gómez, unpublished observations).

Surveillance of insecticide resistance using WHO bioassays accompanied the use of DDT for malaria control until 1992, allowing detection of the first populations with decreased susceptibility to this organochlorine. Quiñones et al. (1987) demonstrated for the first time a resistance to DDT in An. darlingi populations collected from four locations of the municipality of Quibdo, with a mortality percentage between $18-72.3 \%$. In later research, Suárez et al. (1990) confirmed the resistance to DDT in An. darlingi populations located close to the Atrato River in the same municipality. Neither of the mentioned studies determined the mechanism associated with the low mortality found for DDT in this vector. Furthermore, given the high probability of cross-resistance between DDT and pyrethroids, insecticides acting on the same target (the voltage-gated sodium channels) (Soderlund \& Knipple 2003, Brooke 2008), it is of concern that the region of the middle Atrato in Choco where resistance to DDT was determined more than 20 years ago continually uses IRS with lambda-cyhalothrin as their main measure for malaria control.

The pyrethroid insecticides are currently the only class of insecticide approved for ITNs. Unfortunately, resistance to this class of insecticide is increasing despite it being one of the latest classes of chemical pesticide available on the market. These insecticides have a fast action, high potency and are not bioaccumulative, which theoretically help avoid the development of resistance in the short term (Leahey 1985). In the last decade, resistance levels to different pyrethroids have been documented in Anopheles gambiae populations of East and West Africa (Elissa et al. 1993, Chandre et al. 1999a, Vulule et al. 1999), Anopheles funestus of South Africa (Hargreaves et al. 2000, Nikou et al. 2003), Anopheles arabiensis in Tanzania (Kulkarni et al. 2006) and Mozambique (Casimiro et al. 2006) and Anopheles stephensi (Hodjati \& Curtis 1997).

Several authors have reported that the expeditious emergence of resistance to pyrethroids is due to their extensive use in agriculture, and also due to the selection pressure of DDT use for more than 40 years on Anopheles and Aedes aegypti populations (Chandre et al. 1999a, Diabate et al. 2002, 2004). This cross-resistance phenomenon between DDT and pyrethroids was described for the first time in Musca domestica fly (Farnham et al. 1987). More recently, cross-resistance was described in An. gambiae s.s. populations (Chandre et al. 1999b), Anopheles minimus (Theobald) (Chareonviriyaphap et al. 2003) and Culex pipiens (Martinez-Torres et al. 1999). The presence of cross-resistance among different classes of insecticides, either through alterations in the target sites or biochemical detoxification mechanisms could impede the use of specific chemicals in malaria control programs, thus jeopardising the effectiveness of insecticide-treated mosquito nets (Najera \& Zaim 2002).

Although the cross-resistance between DDT/pyrethroids is associated mainly with single nucleotide mutations in the voltage-gated sodium channels, known as $k d r$ resistance (Martínez-Torres et al. 1998, Ranson et al. 2000, Brooke 2008), high levels of detoxifying enzymes have also been shown to be involved (Zerba 1988, Scott \& Kasai 2004). The major enzymatic families associated with resistance include non-specific esterases (NSE), mixed-function oxidases (MFO) and glutathion S-transferases (GST) (Hemingway \& Ranson 2000). The MFO are the enzymes most commonly associated with cross-resistance between DDT/pyrethroids (Scott et al. 1998, Scott \& Wen 2001) and high levels of these enzymes have been found in resistant populations of $A n$. gambiae, An. funestus and An. minimus (Brooke et al. 1999, Vulule et al. 1999, Hargreaves et al. 2000, Rodpradit et al. 2005, Etang et al. 2007). While the esterases are associated mainly with resistance to organophosphates and carbamates, high levels of these enzymes have also been involved with resistance to permethrin in An. gambiae (Vulule et al. 1999), Ae. aegypti (Paeporn et al. 2004, Flores et al. 2005, 2006) and Culex quinquefasciatus (Hamdan et al. 2005).

Despite historical resistance records to DDT in $A n$. darlingi populations in Western Colombia, and given that currently no periodical surveillance of insecticide resistance exists despite the continuous use of chemical control, this paper presents the results of a comparative evaluation of WHO and bottle impregnated bioassays and the biochemical data in An. darlingi populations from three malaria endemic areas in Colombia. Our data is the culmination of a national initiative for malaria and dengue vector evaluation of insecticide resistance. This information will allow for the identification of ineffective insecticides for control of this species and constitutes the first step towards the implementation of a suitable ongoing program for the management of resistance in the areas studied during this research.

\section{MATERIALS AND METHODS}

Study areas and mosquito collection - Five locations having a high potential for insecticide resistance due to the high intensity use of insecticides and endemic levels of malaria, as defined by the presence of autochthonous cases and vector presence were selected (Fig. 1). The five study areas included El Retiro $\left(7^{\circ} 29^{\prime} 39^{\prime \prime} \mathrm{N} 74^{\circ} 52^{\prime} 16^{\prime \prime} \mathrm{W}\right)$, municipality of Zaragoza, state of Antioquia, in the Andean region; Amé-Beté (6 $6^{\circ} 00^{\prime} 00^{\prime \prime} \mathrm{N} 76^{\circ} 78^{\prime} 33^{\prime}$ 'W), municipality of Middle Atrato, state of Chocó, in the Pacific region; El Porvenir $\left(00^{\circ} 14^{\prime} 39.36^{\prime \prime} \mathrm{S} 74^{\circ} 55^{\prime} 31.11^{\prime \prime} \mathrm{W}\right)$, municipality of Puerto Leguízamo, state of Putumayo, in the Amazon region; La Quebradita (00¹5'40.65'S 744ㄴ'10.97' W), municipality of Puerto Leguízamo, state of Putumayo, in the Amazon region; Cecilia Cocha $\left(00^{\circ} 10^{\prime} 22.90^{\prime \prime} \mathrm{S}\right.$ $74^{\circ} 48^{\prime} 55.89^{\prime \prime} \mathrm{W}$ ) and the municipality of Puerto Leguízamo, state of Putumayo, in the Amazon region. 


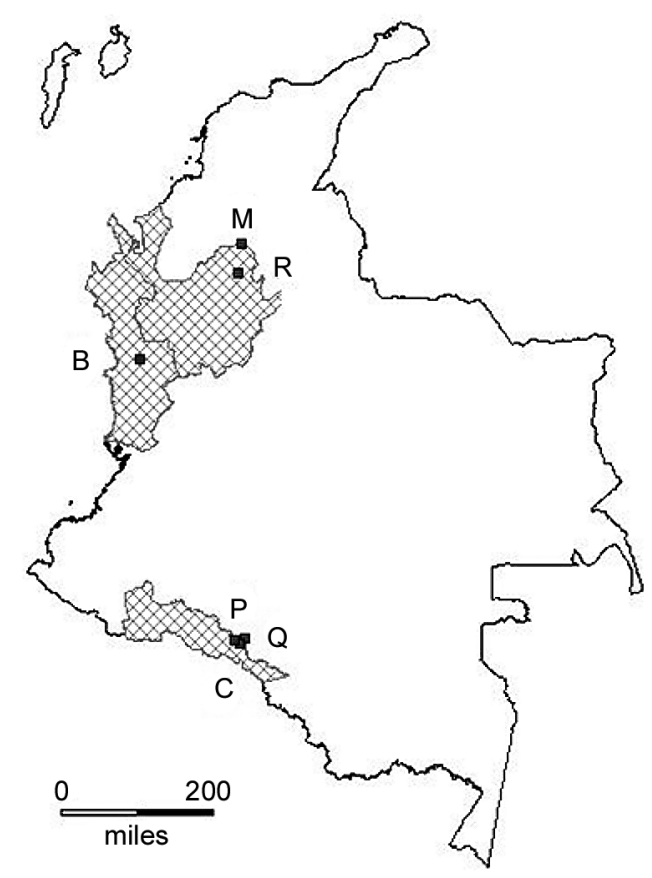

Fig. 1: Colombian map showing the states and localities where Anopheles darlingi was evaluated for insecticide resistance. B: Amé-Beté (state of Chocó); C: Cecilia Cocha (state of Putumayo); M: Malanoche (state of Antioquia); P: El Porvenir (state of Putumayo); Q: La Quebradita (state of Putumayo); R: El Retiro (state of Antioquia).

Each of the five localities is considered to be rural and agricultural. The El Retiro site is located in a gold-bearing zone and the Amé-Beté site is located at the bank of the Atrato River, in an indiscriminate mining zone with plantain, rice and cornfields. The El Porvenir, Cecilia Cocha and La Quebradita sites are each inhabited by native communities lacking public utilities. These communities have an economy based on subsistence agriculture, hunting and fishing. All of the sites sampled have the proper conditions for vector development including an average temperature of $28^{\circ} \mathrm{C}\left(25-30^{\circ} \mathrm{C}\right)$, relative humidity of $90 \%$ and annual average rainfall of $4,250 \mathrm{~mm}^{3}\left(2,500-6,000 \mathrm{~mm}^{3}\right)$. IRS is the main strategy employed for vector control in these areas and lambda-cyhalothrin is the most frequently used compound currently used in the three states.

To date, it is not possible to maintain colonies of $A n$. darlingi under laboratory conditions. Due to this breeding restraint, there are no susceptible populations for this species currently available as a reference evaluation of insecticide resistance levels. However, it is known that natural field populations with low or no insecticide pressure could be used as susceptibility controls in this particular condition. Regarding the need for a reference population, the Malanoche site $\left(08^{\circ} 05^{\prime} 47^{\prime \prime} \mathrm{N}\right.$ $\left.74^{\circ} 46^{\prime} 33^{\prime \prime} \mathrm{O}\right)$, municipality of Nechí, state of Antioquia, in the Andean region, was selected. This locality has not been a target for extensive insecticide control in the last
10 years; therefore, this population was used to establish diagnostic doses for bottle bioassays and as a baseline for comparing enzyme levels.

Adult female Anopheles sp. were collected by human landing catches, following the recommendations of the WHO. Prior approval by the Ethical Committee of the Sede de Investigación Universitaria, University of Antioquia, was obtained. All of the collections were conducted between 17:30-22 h, from May-November 2006. Due to the difficulties of colonising this species in the lab, all of the susceptibility bioassays were conducted directly in the field in the early morning after the night of collection. All specimens were then transported in silica gel to the laboratory for species identification. Samples for biochemical analysis were transported frozen and not thawed during the transport from field to lab.

Identification of species - The taxonomical identification of mosquitoes was completed through observation of the morphological characters of the females using characteristics of wings and posterior legs, compared and contrasted with conventional taxonomic keys (Faran 1980, Faran \& Linthicum 1981).

Insecticides - Insecticides frequently used by vector control programs in the selected study areas were chosen to evaluate the toxicity, resistance/cross-resistance patterns and possible mechanisms involved in resistance in $A n$. darlingi. These insecticides represented multiple classes of insecticides with various modes of action. The pyrethroids: lambda-cyhalothrin (99\%), deltamethrin (99.9\%) and permethrin $(99 \%)$, the organophosphates: fenitrothion $(99.5 \%)$ and malathion (98\%) and the organochlorine DDT $(92.4 \%)$ were evaluated. All insecticides used for bottle impregnation were purchased as technical grade insecticides from Chem Service (West Chester, PA, USA).

WHO bioassays - The standardised WHO protocol (WHO 1981, 1998) was implemented using their susceptibility diagnostic kit and impregnated papers (WHO, Geneva). On average, 180 non-blood-fed females were evaluated for each insecticide at each site. The distinguishing of fed from unfed females was conducted by examination of the abdominal appearance. Control mosquitoes were exposed to papers impregnated with solvent only. Mosquitoes were exposed for $1 \mathrm{~h}$ to lambdacyhalothrin $(0.05 \%)$, deltamethrin $(0.05 \%)$, permethrin $(0.75 \%)$, malathion (5\%) and DDT $(4 \%)$ and for $2 \mathrm{~h}$ to fenitrothion (1\%) (Brooke et al. 2001). Each bioassay was carried out with four tubes, one control and three treatments with 20 mosquitoes per tube. Bioassays were performed in triplicate. Mortality was recorded at $24 \mathrm{~h}$ post-exposure and all surviving mosquitoes were contained and given sugar solution at $10 \%$.

CDC bottle bioassays - Bottles were prepared following the Brogdon and McAllister (1998) protocol. Each population was evaluated with diagnostic doses and times previously established for An. darlingi (FonsecaGonzález 2008). Fifteen-twenty non-blood-fed females from each site were introduced in $250 \mathrm{~mL}$ glass bottles impregnated with the diagnostic dose of the respective insecticide. Each test consisted of four impregnated bot- 
tles and one control bottle. The control bottle contained ethanol with no insecticide. At least three tests were conducted for each insecticide and population. Immediately prior to use, all insecticide solutions were prepared fresh from stock solutions. At $15 \mathrm{~min}$ intervals, the number of live and dead mosquitoes in each bottle was recorded. This process was repeated for 1.5-2 $\mathrm{h}$ or until all of the mosquitoes were deceased. The mortality criteria included mosquitoes with difficulties flying or standing on the bottle's surface.

Biochemical tests - A total of 90-120 adult females were collected at each study site and frozen at $-70^{\circ} \mathrm{C}$ prior to biochemical analysis. The NSE, MFO, GST and modified acetylcholinesterase (MACE) activities were determined according to the methodology described by Brogdon (1988), Brogdon and Barber (1990a, b) and Brogdon et al. (1997). Briefly, the head and thorax from females were homogenised individually in $100 \mu \mathrm{L}$ of $0.01 \mathrm{M}$ potassium phosphate buffer, $\mathrm{pH} 7.2$, and suspended in $1 \mathrm{~mL}$ of the same buffer. Aliquots of $50 \mu \mathrm{L}$ were then transferred to microtiter plate wells. Thirty mosquitoes were analysed per plate in triplicate. Replicates with a variation coefficient that was higher than 0.15 were discarded in order to avoid differences produced by possible manual errors. All enzymatic reactions were conducted at rt. NSE levels were measured at $540 \mathrm{~nm}$ after $10 \mathrm{~min}$ incubation with $3 \mathrm{mM} \beta$-naphthyl acetate. For the MFO assay, absorbance was measured at $620 \mathrm{~nm}$ after 5 min incubation with 2 mM 3,3',5,5'-tetramethyl-benzidina. GST levels were measured in the reaction containing $2 \mathrm{mM}$ reduced glutathione and $1 \mathrm{mM}$ 1-chloro-2,4-dinitrobenzene. The reaction rates were measured at $340 \mathrm{~nm}$ at $5 \mathrm{~min}$. MACE levels were measured in the reaction containing $2.6 \mathrm{mM}$ acetylthiocholine iodide, $0.3 \mathrm{mM}$ dithio-bis-2-nitrobenzoic acid and $100 \mathrm{mM}$ propoxur. The reaction rates were measured at $414 \mathrm{~nm}$ at $10 \mathrm{~min}$. The total protein concentration for each sample was determined using the Bradford (1976) method with Brogdon's modifications (Brogdon 1984a, b). This allowed detection of differences in body mass of the mosquitoes, which was used as a correction factor for the enzyme analysis. At least, three positive and negative controls per plate were used. The negative control absorbance was subtracted from the value for each mosquito for each enzyme thus elimi- nating the reaction background. The Malanoche strain was used as a susceptible standard population in all of the biochemical analysis performed.

Data analysis - A modified Abbott's formula (1925) was used to correct for the mortality observed in the bioassays when the mortality in the control was between $5-20 \%$ (WHO 1998). The resistance status was evaluated in accordance with WHO guidelines (1981, 1998). The bioassay data with bottles were graphed using the JMP program (version 3.2.6; SAS Institute Inc), as time vs. mortality percentage. All mosquitoes surviving the dose and diagnostic time established with the reference population were considered to be resistant (Brogdon \& McAllister 1998). In order to determine significant differences in the enzymatic levels in each population, the enzymatic profiles were compared with those obtained for the susceptible strain by Kruskal-Wallis and Tukey's non parametric tests $(\mathrm{p}<0.05)$.

\section{RESULTS}

WHO bioassays - Due to the low mosquito densities coupled with the high diversity of Anopheles species present at the El Retiro site, it was not possible to carry out evaluations using the WHO methodology at this location.

The average mortality percentages found with six insecticides, using impregnated papers with the WHO diagnostic doses are shown in Table. The three populations evaluated in the state of Putumayo showed mortality rates higher than $95 \%$, indicating susceptibility to all insecticides tested in this study. The Amé-Beté population showed total susceptibility to the organophosphates, malathion and fenitrothion, with mortality rates of $95 \%$ and $100 \%$, respectively. In addition, this population showed reduced susceptibility to the pyrethroids deltamethrin and permethrin with mortality rates of $84 \%$ and $88 \%$, respectively. This population also demonstrated resistance to lambda-cyhalothrin and DDT, with mortality rates of $68 \%$ for both insecticides.

CDC bottle bioassays - The results obtained with CDC bottles, using diagnostic doses established specifically for An. darlingi (Fonseca-González 2008) are shown in Fig. 2A-F. Using this methodology, susceptibility to the pyrethroids lambda-cyhalothrin, deltamethrin

TABLE

WHO bioassay mortality rates of An. darlingi expressed as percentages. Mortality rates below $80 \%$ are consistent with insecticide resistance

\begin{tabular}{lllcccccc}
\hline & & \multicolumn{5}{c}{ Insecticides $^{a}$} \\
\hline State & Municipality & Locality & Lambda-cyhalothrin & Deltamethrin & Permethrin & Fenitrothion & Malathion & DDT \\
\hline Antioquia & Nechí & Malanoche & $100 \pm 0$ & $100 \pm 0$ & $100 \pm 0$ & $100 \pm 0.6$ & $100 \pm 0$ & $100 \pm 0$ \\
Chocó & Medio Atrato & Amé-Beté & $68 \pm 4.3$ & $84 \pm 1.8$ & $88 \pm 2.8$ & $100 \pm 0.9$ & $95 \pm 2.5$ & $68 \pm 3.5$ \\
Putumayo & Puerto Leguizamo & El Porvenir & $99 \pm 1.4$ & $98 \pm 2.0$ & $100 \pm 0$ & $98 \pm 1.1$ & $100 \pm 0.7$ & $95 \pm 4.8$ \\
& Puerto Leguizamo & Cecilia Cocha & $98 \pm 1.0$ & $100 \pm 0.6$ & $100 \pm 0$ & $99 \pm 2.4$ & $100 \pm 0$ & $98 \pm 5.7$ \\
& Puerto Leguizamo & La Quebradita & $100 \pm 0$ & $98 \pm 3.4$ & $100 \pm 0$ & $100 \pm 0.5$ & $100 \pm 1.2$ & $97 \pm 3.2$ \\
\hline
\end{tabular}

$a$ : values are the mean $\pm \mathrm{SD}$. Three assays were performed per insecticide at each site. 
and permethrin was identified at the El Retiro, El Porvenir, La Quebradita and Cecilia Cocha sites (Fig. 2A-C). In agreement with the WHO bioassays, the Amé-Beté site displayed a strong resistance to lambda-cyhalothrin, with a mortality rate of $65 \%$ (Fig. 2A) and decreased susceptibility to deltamethrin and permethrin with mortalities of $94 \%$ and $85 \%$, respectively (Fig. 2B-C). For DDT, susceptibility in all populations was observed, except for Amé-Beté, which showed resistance to this insecticide (Fig. 2D). One hundred percent mortality for this population was only reached after $2 \mathrm{~h}$ of exposure to the insecticide in comparison with the other populations, where total mortality was observed after only $1 \mathrm{~h}$ of insecticide exposure. Evaluation of the organophosphates showed susceptibility to malathion in all field populations (Fig. 2F). The mortality levels found for fenitrothion corresponded with susceptibility in all of the populations studied, although the La Quebradita population displayed a decrease in susceptibility $(83 \%$ mortality) (Fig. 2E).

Biochemical tests - The levels of four enzymatic systems associated with insecticide resistance are shown in Fig. 3A-D. Enzyme absorbances were compared against the Malanoche An. darlingi natural susceptible strain. Protein levels were consistent and no corrections for mosquito size variation were necessary. The average absorbances for MFO and NSE enzymes were found to be significantly higher in mosquitoes from Amé-Beté $(\mathrm{p}<$ 0.0001 ) (Fig. 3A, B), but in none of the other populations evaluated or in the Malanoche population. The increase in MFO and NSE levels may be correlated with lambdacyhalothrin and DDT resistance observed in Amé-Beté population. No evidence of MACE activity was found in the six populations of An. darlingi that were evaluated $(p>0.05)$ (Fig. 3C). All three populations from the municipality of Puerto Leguízamo showed high levels of GST ( $p<0.001)$. However, this high GST level is not correlated with the susceptible status because all of these populations were susceptible to both DDT and the pyrethroids. Mosquitoes from El Retiro and Amé-Beté do not show GST levels significantly higher than those found for the reference population (Fig. 3D).

\section{DISCUSSION}

Chemical insecticide spraying is the most effective control strategy in the ongoing battle against malaria. Unfortunately, the growing development of insecticide resistance threatens this control strategy, compromising vector control programs in regions where resistance is reported in vector insects.

This study documented the susceptibility status to three pyrethroids, two organophosphates and DDT in An. darlingi populations collected from three states with active malaria transmission. Using the WHO recommended mortality level (under $80 \%$ ) as the resistance threshold, all field populations remain susceptible to the insecticides malathion, fenitrothion, deltamethrin and permethrin. Notwithstanding, the population of La Quebradita showed a mortality rate of $83 \%$ to fenitrothion and the population of Amé-Beté showed a mortality level of $84 \%$ to permethrin; while these mortality rates are not considered resistant by the WHO standards, they indicate that more than $15 \%$ of insects are surviving the effects of these insecticides. This is an alarming result and increases in monitoring of these populations is necessary. This is especially true because permethrin is one of the recommended insecticides for ITNs, one of the malaria control interventions currently most promoted (Lengeler \& Sharp 2003).

Based on our results, only the An. darlingi population at the municipality of Middle Atrato (Chocó) is resistant to both lambda-cyhalothrin and DDT. Mosquito
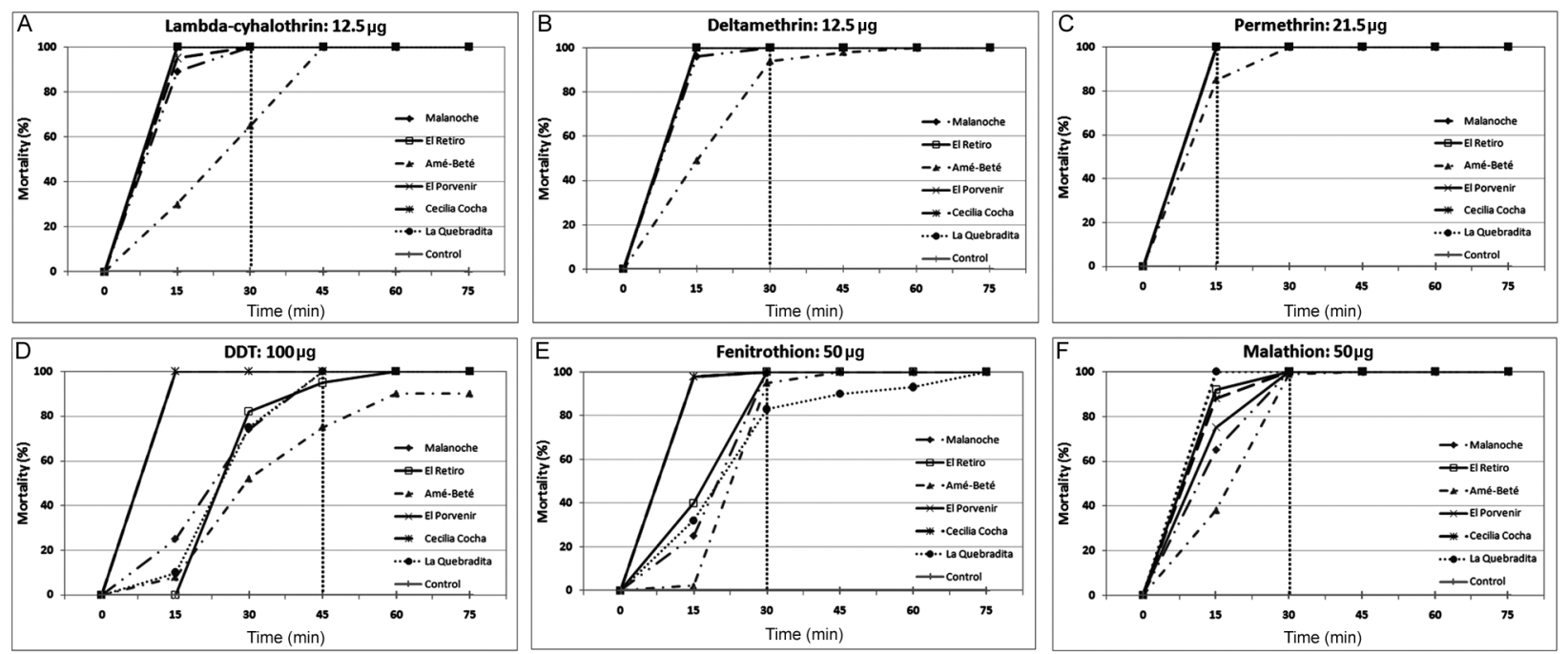

Fig. 2: CDC bottle bioassay mortality rates expressed as percentages. Susceptibility threshold established with diagnostic doses in the reference population (Malanoche) is shown in dotted lines. A: Lambda-cyhalothrin: $12.5 \mu \mathrm{g}, 30 \mathrm{~min}$; B: Deltamethrin: $12,5 \mu \mathrm{g}, 30 \mathrm{~min}$; C: Permethrin: $21.5 \mu \mathrm{g}, 15 \mathrm{~min}$; D: DDT: $100 \mu \mathrm{g}$, $45 \mathrm{~min}$; E: Fenitrothion: $50 \mu \mathrm{g}, 30 \mathrm{~min}$; F: Malathion: $50 \mu \mathrm{g}, 30 \mathrm{~min}$. 
A

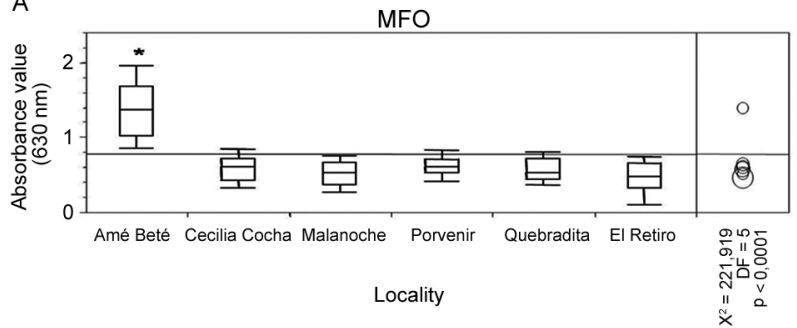

$\mathrm{C}$

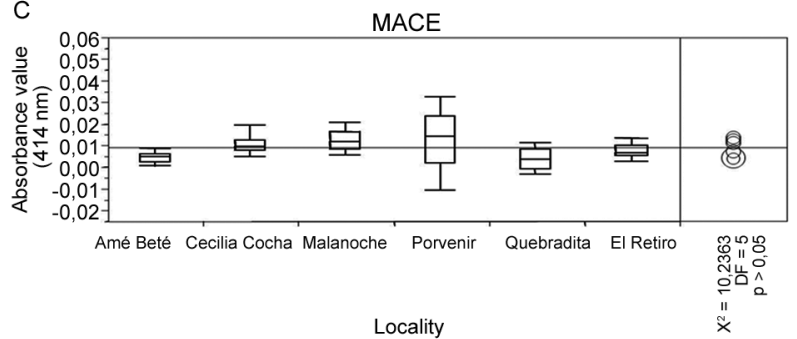

B

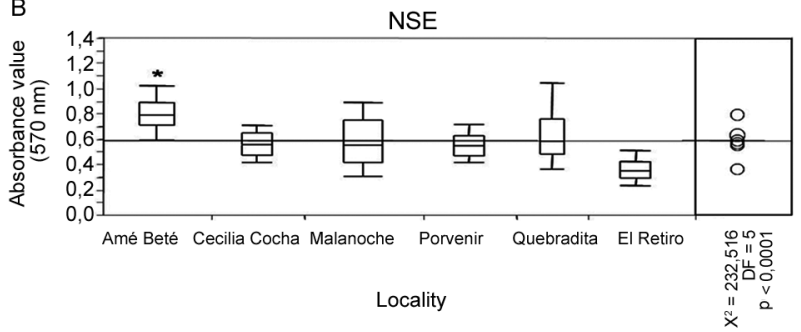

$\mathrm{D}$

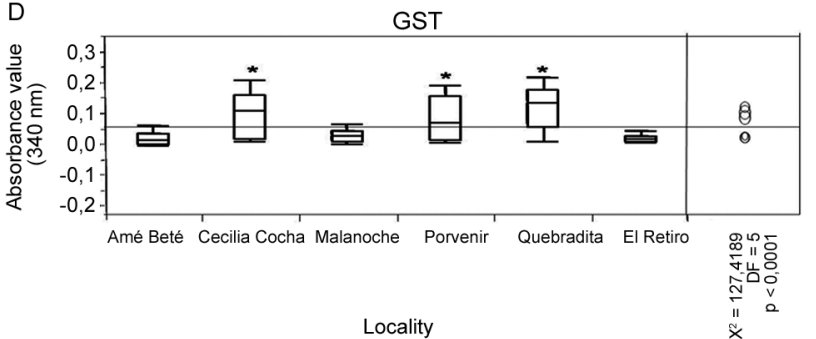

Fig. 3: box-plot of corrected absorbance values for enzyme activities. Anopheles darlingi populations with elevated enzymatic activity in comparison with Malanoche strain are marked with asterisck. A: mixed-function oxidases (MFO); B: non-specific esterases (NSE); C: modified acetylcholinesterase (MACE); D: glutathione S-transferases (GST).

populations from the states of Antioquia and Putumayo retain their susceptibility status to all insecticides evaluated. Chocó is one of the four states located in the Pacific region of Colombia and reports the highest number of malaria cases caused by P. falciparum. Of all cases reported in Colombia during 2006, 6,965 (7.75\%) were from this state and 4,358 were diagnosed as cerebral malaria, resulting in five fatalities. The transmission of malaria in Chocó is active in all municipalities of the state and the risk varies from medium $(>1$ case $/ 1000$ inhabitants) to high (> 10 cases/1000 inhabitants). Deficiencies in home structure, lack of utilities, low social economic level of the population and the close proximity of homes to watered fields, bodies of water and territories rich in vegetation, where there is a greater availability of mosquito breeding sites, contributes to the local transmission of malaria at eight urban centres, including the capital, Quibdo (Montoya et al. 2000).

Previous studies have suggested that An. darlingi, Anopheles nuneztovari and Anopheles albimanus are involved in the transmission of malaria in this state, which has resulted in a limiting of the fight against malaria to the use of chemical pesticides in strategies of IRS and ITNs as vector control methods.

Historically, IRS with DDT is recorded for malaria control from 1959 until 1992, when this insecticide was discontinued for any insect control program in Colombia (Resolution 10255, 1993, Ministry of Health). In more recent years, organophosphates such as fenitrothion have been used and most recently the pyrethroids lambda-cyhalothrin and deltamethrin have been used. These are the most commonly used insecticides in urban and rural areas of Colombia.

The exclusive use of lambda-cyhalothrin for vector control in Chocó has resulted in resistance to this insecti- cide in An. darlingi. Quiñones et al. (1987) and Suárez et al. (1990) reported DDT resistance in this same population using the WHO bioassays. More than 20 years after these studies, DDT resistance is maintained in this vector despite this insecticide not being used during the last 17 years. Stability in the level of DDT resistance, added to the resistance of lambda-cyhalothrin found in this population could be the result of cross-resistance between these two insecticides. The pyrethroids and DDT act directly on the sodium channels of the central nervous system, increasing the conduction of sodium ions during the neuronal excitement process (Soderlund \& Bloomquist 1989). Mutations in this protein known as resistance type $k d r$ and super $k d r$ cause a decrease in the sensibility to DTT/pyrethroids, altering the sites of union to insecticides and causing functional changes in the properties of the sodium channels (Ffrench-Constant et al. 1998).

The possibility that this mechanism was present in the Amé-Beté population was explored using the primers previously described for the two variables of the $k d r$ mutation found in An. gambiae (data not shown) (MartínezTorres et al. 1998, Ranson et al. 2000). No amplification of this gene was discovered in any of the samples evaluated; therefore, this mechanism could not be evaluated in our studies. A future goal is to determine the protein sequence of the sodium channel in An. darlingi populations, which will allow for the designing of a specific $k d r$-assay, which may be useful in the identification of multiple mutations associated with this insecticide resistance mechanism in this species. Another important issue regarding to $k d r$-type insensitivity is related to the knockdown (KD) effect. Considering data in some malaria African mosquito populations that indicate a significant increase in KD time observed before any decrease in mortality (Chandre et al. 1999a) and WHO suggestions 
that changes in the KD rate of mosquitoes can be a sensitive indicator for early detection of pyrethroid resistance (WHO 1998), it is important for the inclusion of KD rate during the bioassays in order to have more useful tools for the surveillance of insecticide resistance.

The persistence of DDT resistance could also be the result of the fixation of resistant alleles, with the subsequent elimination of susceptible alleles, as a consequence of the pervasive use of DDT during the course of more than 40 years. This can only be proved through molecular tests evaluating the homogeneity of the genetic background in this An. darlingi population. For a population to be selected in favour of insecticide resistance, it is expected to have a low heterozygosity value. However, González et al. (2007) evaluated the genetic structure of this same population from Chocó and using molecular markers as Random Amplified Polymorphic DNA and Amplified Fragment Length Polymorphism, did not find evidence of low variability. Indeed, the expected heterozygosity was high $(\mathrm{H}=0.3706)$. This level is the same as the level of genetic flow with the An. darlingi population collected in the locality of Tierralta (state of Cordoba, Colombia), which has probably allowed dissemination and maintenance of the resistant alleles. Nevertheless, the neutral molecular markers such as the ones used in this study do not permit us to infer the actual effect of selection on specific resistant alleles.

MFO and to a lesser extent the NSE, are the most commonly found enzymes involved in the metabolic detoxification of pyrethroids and DDT (Scott \& Wen 2001). The microplate biochemical tests performed in this study demonstrated elevated levels of MFO and NSE in the Amé-Beté population, suggesting that detoxification by these enzymes could be implicated in the cross-resistance between these two insecticides. No other populations in this study showed elevated levels of these enzymes. This is the first time that the presence of high enzymatic levels was demonstrated as a possible resistance mechanism in An. darlingi, one of the main malaria vectors in South America. Inhibitors of these enzymatic systems have the ability to increase insecticide action. In order to confirm that the resistance found in the Middle Atrato population is metabolic, it is necessary to carry out bioassays with MFO and NSE inhibitors such as piperonyl butoxide or DEF (S,S,S,-tributyl phosphorotrithioate), which can identify the impact of these enzymes on the toxicity of lambda-cyhalothrin and DDT (Ranasinghe \& Georghiou 1979).

The high levels of GST discovered in the Putumayo populations did not correlate with the susceptibility phenotype determined for the insecticides that we evaluated. It is probable that this enzymatic activity is an unrelated physiologic effect independent from the resistance status of these populations. There is also the possibility that these high levels were due to insecticide pressure and this hypothesis must be considered. We recommend frequent monitoring of the susceptibility levels in this population.

Resistance to lambda-cyhalothrin and DDT in the Amé-Beté population was detected through the use of both WHO and CDC methodologies. The comparison between the assays with bottles and papers was pos- sible for all of the insecticides in all populations, with the exception of El Retiro, where it was not possible to carry out the WHO bioassays. It was not possible to obtain a significant amount of An. darlingi mosquitoes from this site due to the high diversity of species found in the area. All of the results were comparable between the two methodologies, indicating that both of the methodologies are useful for determining the susceptibility status of mosquito populations in Colombia. The CDC bioassay was also evaluated with two other malaria vector species, An. albimanus and An. nuneztovari, and the dengue vector, Ae aegypti, in Colombia (Fonseca-González 2008). This methodology was also evaluated in other countries, such as Brazil, Mexico and Thailand, for insecticide resistance surveillance in $A e$. aegypti (Saelim et al. 2005, Flores et al. 2006, Montella et al. 2007). Once the diagnostic doses for the bottles is determined, the evaluation results can be obtained more quickly (1-2 h), without limitations in the number of times the bottles can be used, doses or formulations. The combination with sinergists can be included, allowing for identification of the active resistance mechanisms in evaluated populations.

Diagnostic doses used in this study could be a reference for future national and local evaluations.

Our data provide evidence to support against reintroduction of DDT for vector control in malaria prevention, at least in the Pacific region of Colombia. Our results also emphasise the need for implementation and maintenance of permanent monitoring programs that record susceptibility levels of mosquitoes to insecticides in populations subjected to chemical control measures.

\section{ACKNOWLEDGMENTS}

To the Coordinators and the staff of Vector-Borne Diseases Sections from Antioquia, Chocó and Putumayo Health Secretaries, to the staff of the Entomology Branch at the Centers for Disease Control and Prevention in Atlanta, for their technical assistance, especially to Audrey Lenhart, Tara Brant and Elien E. Wilkins.

\section{REFERENCES}

Abbott WS 1925. A method of computing the effectiveness of an insecticide. J Econ Entomol 18: 265-267.

Bradford MM 1976. A rapid and sensitive method for the quantitation of microgram quantities of protein utilizing the principle of protein-dye binding. Anal Biochem 72: 248-254.

Brogdon WG 1984a. Mosquito protein microassay. I. Protein determinations from small portions of single-mosquito homogenates. Comp Biochem Physiol B 79: 457-459.

Brogdon WG 1984b. Mosquito protein microassay. II. Modification for potential field use. Comp Biochem Physiol B 79: 461-464.

Brogdon WG 1988. Microassay of acetylcholinesterase activity in small portions of single mosquito homogenates. Comp Biochem Physiol C 90: 145-150.

Brogdon WG, Barber AM 1990a. Microplate assay of glutathione s-transferase activity for resistance detection in single-mosquito triturates. Comp Biochem Physiol B 96: 339-342.

Brogdon WG, Barber AM 1990b. Fenitrothion-deltamethrin crossresistance conferred by esterases in Guatemalan Anopheles albimanus. Pestic Biochem Physiol 37: 130-139. 
Brogdon WG, McAllister JC 1998. Resistance and vector control. Emerg Infect Dis 4: 605-613.

Brogdon WG, McAllister JC, Vulule J 1997. Heme peroxidase activity measured in single mosquitoes identifies individuals expressing an elevated oxidase for insecticide resistance. J Am Mosq Control Assoc 13: 233-237.

Brooke BD 2008. $K d r$ : can a single mutation produce an entire insecticide resistance phenotype? Trans $R$ Soc Trop Med Hyg 102: 524-525.

Brooke BD, Hunt RH, Koekemoer LL, Dossou-Yovo J, Coetzee M 1999. Evaluation of a PCR assay for detection of pyrethroid insecticide resistance in the malaria vector species of the Anopheles gambiae complex (Diptera: Culicidae). J Am Mosq Control Assoc 15: 565-568.

Brooke BD, Kloke G, Hunt RH, Koekemoer LL, Temu EA, Taylor ME, Small G, Hemingway J, Coetzee M 2001. Bioassay and biochemical analyses of insecticide resistance in Southern African Anopheles funestus (Diptera: Culicidae). Bull Entomol Res 91: 265-272.

Casimiro S, Coleman M, Hemingway J, Sharp B 2006. Insecticide resistance in Anopheles arabiensis and Anopheles gambiae from Mozambique. J Med Entomol 43: 276-282.

Chandre F, Darriet F, Manga L, Akogbeto M, Fay O, Mouchet J, Guillet P 1999a. Status of pyrethroid resistance in Anopheles gambiae sensu lato. Bull World Health Organ 77: 230-234.

Chandre F, Darriet F, Manguin S, Brengues C, Carnevale P, Guillet P 1999b. Pyrethroid cross-resistance spectrum among populations of Anopheles gambie from Cote d'Ivoire. J Am Mosq Control Assoc 15: 53-59.

Chareonviriyaphap T, Rongnoparut P, Chantarumporn P, Bangs MJ 2003. Biochemical detection of pyrethroid resistance mechanisms in Anopheles minimus in Thailand. J Vector Ecol 28: 108-116.

Diabate A, Baldet T, Chandre F, Akogbeto M, Guiguemde TR, Darriet F, Brengues C, Guillet P, Hemingway J, Small G, Hougard $\mathrm{JM} 2002$. The role of agricultural use of insecticides in resistance to pyrethroids in An. gambiae sl in Burkina Faso. Am J Trop Med Hyg 67: 617-622.

Diabate A, Brengues C, Baldet T, Dabire KR, Hougard JM, Akogbeto M, Kengne P, Simard F, Guillet P, Hemingway J, Chandre F 2004. The spread of the Leu-Phe $k d r$ mutation through Anopheles gambiae complex in Burkina Faso: genetic introgression and de novo phenomena. Trop Med Int Health 9: 1267-1273.

Elissa N, Mouchet J, Riviere F, Meunier JY, Yao K 1993. Resistance of Anopheles gambiae ss to pyrethroids in Cote d'Ivoire. Ann Soc Belg Med Trop 73: 291-294.

Etang J, Manga L, Toto JC, Guillet P, Fondjo E, Chandre F 2007. Spectrum of metabolic-based resistance to DDT and pyrethroids in Anopheles gambiae s.l. populations from Cameroon. $J$ Vector Ecol 32: 123-133.

Faran M 1980. Mosquito studies (Diptera: Culicidae). XXXIV A revision of the Albimanus section of the subgenus Nyssorhynchus of Anopheles. Contrib Amer Entomol Inst 15: 1-215.

Faran M, Linthicum K 1981. A handbook of the Amazonian species of Anopheles (Nyssorhynchus) (Diptera: Culicidae). Mosq Syst 13: 1-81.

Farnham AW, Murray AWA, Sawicki RM, Denholm I, White JC 1987. Characterization of the structure-activity relationship of $k d r$ and 2 variants of super $k d r$ to pyrethroids in the housefly Musca domestica L. Pestic Sci 19: 209-220.

Ffrench-Constant RH, Pittendrigh B, Vaughan A, Anthony N 1998. Why are there so few resistance-associated mutations in insecticide target genes? Philos Trans R Soc Lond B Biol Sci 353: 1685-1693.
Flores AE, Albeldaño-Vázquez W, Salas IF, Badii MH, Loaiza H, Garcia GP, Lozano S, Brogdon WG, Black IVWC, Beaty B 2005. Elevated alfa-esterases levels associated with permethrin tolerance in Aedes aegypti (L.) from Baja California, Mexico. Pestic Biochem Physiol 82: 66-78.

Flores AE, Grajales JS, Salas IF, Garcia GP, Becerra MH, Lozano S, Brogdon WG, Black WC, Beaty B 2006. Mechanisms of insecticide resistance in field populations of Aedes aegypti (L.) from Quintana Roo, Southern Mexico. J Am Mosq Control Assoc 22: 672-677.

Fonseca-González I 2008. Estatus de la resistencia a insecticidas de los vectores primarios de malaria y dengue en Antioquia, Chocó, Norte de Santander y Putumayo, Colombia, PhD Thesis, Universidad de Antioquia, $183 \mathrm{pp}$.

Gonzalez R, Wilkerson R, Suarez MF, García F, Gallego G, Cardenas $\mathrm{H}$, Posso CE, Duque MC 2007. A population genetics study of Anopheles darlingi (Diptera: Culicidae) from Colombia based on random amplified polymorphic DNA-polimerase chain reaction and amplified fragment length polymorphism markers. Mem Inst Oswaldo Cruz 102: 255-262.

Hamdan H, Sofian-Azirun M, Nazni WA, Lee HL 2005. Insecticide resistance development in Culex quinquefasciatus (Say), Aedes aegypti (L.) and Aedes albopictus (Skuse) larvae against malathion, permethrin and temephos. Trop Biomed 22: 45-52.

Hargreaves K, Koekemoer LL, Brooke BD, Hunt RH, Mthembe J, Coetzee M 2000. Anopheles funestus resistant to pyrethroid insecticides in South Africa. Med Vet Entomol 2: 181-189.

Hemingway J, Ranson H 2000. Insecticide Resistance in insect vectors of human disease. Annu Rev Entomol 45: 371-391.

Hodjati MH, Curtis CF 1997. Dosage differential effects of permethrin impregnated into bednets on pyrethroid resistant and susceptible genotypes of the mosquito Anopheles stephensi. Med Vet Entomol 11: 368-372.

Kulkarni MA, Rowland M, Alifrangis M, Mosha FW, Matowo J, Malima R, Peter J, Kweka E, Lyimo I, Magesa S, Salanti A, Rau ME, Drakeley C 2006. Occurrence of the leucine-to-phenylalanine knockdown resistance $(k d r)$ mutation in Anopheles arabiensis populations in Tanzania, detected by a simplified high-throughput SSOP-ELISA method. Malar J 5: 56-61.

Leahey JP 1985. The Pyrethroid insecticides, Taylor \& Francis, London, $440 \mathrm{pp}$.

Lengeler C, Sharp B 2003. Indoor residual spraying and insecticidetreated nets. In Reducing malaria's burden: evidence of effectiveness for decision makers, GlobalHealth Council, Washington, $\mathrm{p}$. $17-24$.

Martinez-Torres D, Chandre F, Williamson MS, Darriet F, Berge JB, Devonshirre AL, Guillet P, Pasteur N, Pauron D 1998. Molecular characterization of pyrethroid knockdown resistance $(k d r)$ in the major malaria vector Anopheles gambiae s.s. Insect Mol Biol 7: 179-184.

Martinez-Torres D, Chevillon C, BrunBarale A, Bergé JB, Pasteur N, Pauron D 1999. Voltage-dependent $\mathrm{Na}+$ channels in pyrethroidresistant Culex pipiens L mosquitoes. Pestic Sci 55: 1012-1020.

Montella IR, Martins AJ, Viana-Medeiros PF, Lima JB, Braga IA, Valle D 2007. Insecticide resistance mechanisms of Brazilian $A e$ des aegypti populations from 2001 to 2004. Am J Trop Med Hyg 77: 467-477.

Montoya R, Padilla J, Cepeda I 2000. Epidemiological situation of malaria in Colombia. Report of the Ministry of Health of Colombia, Santafe de Bogotá, 80 pp.

Najera JA, Zaim M 2002. Malaria Vector Control: Decision making criteria and procedures for judicious use of insecticides. WHO Pesticide Evaluation Scheme (WHOPES), World Health Organization, Geneva, $106 \mathrm{pp}$. 
Nikou D, Ranson H, Hemingway J 2003. An adult-specific CYP6 $P 450$ gene is overexpressed in a pyrethroid-resistant strain of the malaria vector, Anopheles gambiae. Gene 318: 91-102.

Olano VA, Brochero HL, Saénz R, Quiñones ML, Molina JA 2001. Mapas preliminares de la distribución de especies de Anopheles vectores de malaria en Colombia. Biomédica 21: 402-408.

Paeporn P, Supaphathom K, Srisawat R, Komalamisra N, Deesin V, Ya-umphan P, Leeming Sawat S 2004. Biochemical detection of pyrethroid resistance mechanism in Aedes aegypti in Ratchaburi province, Thailand. Trop Biomed 21: 145-151.

PAHO - Pan American Health Organization 2005. Malaria: Step up the fight. PAHO Today, Washington DC, p. 5.

Quiñones ML, Suarez MF, Fleming GA 1987. Estado de la susceptibilidad al DDT de los principales vectores de malaria en Colombia y su implicación epidemiológica. Biomédica 7: 81-86.

Ranasinghe LE, Georghiou GP 1979. Comparative modification of insecticide resistance spectrum in Culex pipiens fatigans Wied, by selection with temephos and temephos synergist combinations. Pestic Sci 10: 510-518.

Ranson H, Jenson B, Vulule JM, Wang X, Hemingway J, Collins FH 2000. Identification of a novel mutation in the voltage-gated sodium channel gene of Anopheles gambiae associated with resistance to pyrethroid insecticides. Insect Mol Biol 9: 491-498.

Rodpradit P, Boonsuepsakul S, Chareonviriyaphap T, Bangs MJ, Rongnoparut P 2005. Cytochrome P450 genes: molecular cloning and overexpression in a pyrethroid-resistant strain of Anopheles minimus mosquito. J Am Mosq Control Assoc 21: 71-79.

Saelim V, Brogdon WG, Rojanapremsuk J, Suvannadabba S, Pandii W, Jones JW, Sithiprasasna R 2005. Bottle and biochemical assays on temephos resistance in Aedes aegypti in Thailand. Southeast Asian J Trop Med Public Health 36: 417-425.

Scott JG, Kasai S 2004. Evolutionary plasticity of monooxygenasemediated resistance. Pestic Biochem Physiol 78: 171-178.

Scott JG, Liu N, Wen Z 1998. Insect cytochromes P450: diversity, insecticide resistance and tolerance to plant toxins. Comp Biochem Physiol C 121: 147-155.
Scott JG, Wen Z 2001. Cytochromes P450 of insects: the tip of the iceberg. Pest Manag Sci 57: 958-967.

Sivigila 2007. Estadísticas de la vigilancia en salud pública. Bogotá: Instituto Nacional de Salud [updated 2008 May 12]. Available from: http://www.ins.gov.co/.

Soderlund DM, Bloomquist JR 1989. Neurotoxic action of pyrethroid insecticides. Annu Rev Entomol 34: 77-96.

Soderlund DM, Knipple DC 2003. The molecular biology of knock down resistance to pyrethroid insecticides. Insect Biochem Mol Biol 33: 563-577.

Suárez MF, Quiñones ML, Palacios JD, Carrillo A 1990. First record of DDT resistance in Anopheles darlingi. J Am Mosq Control Assoc 6: 72-74.

Vulule JM, Beach RF, Atieli FK, McAllister J, Brogdon WG, Roberts JM, Mwangi RW, Hawley WA 1999. Elevated oxidase and esterase levels associated with permethrin tolerance in Anopheles gambiae from Kenyan villages using permethrin-impregnated nets. Med Vet Entomol 13: 239-244.

WHO - World Health Organization 1981. Instructions for determining the susceptibility or resistance of adult mosquitoes to organochlorine, organophosphate and carbamate insecticides - Diagnostic test. Document WHO/VBC/81.806. WHO, Geneva, 7 pp.

WHO - World Health Organization 1993. A global malaria control strategy, WHO, Geneva, 30pp.

WHO - World Health Organization 1998. Test procedures for insecticide resistance monitoring in malaria vectors, bio-efficacy and persistence of insecticides on treated surfaces (WHO/CDS/CPC/ MAL/98.12), WHO, Geneva, 46 pp.

WHO - World Health Organization 2005a. World malaria report. Roll Back Malaria, United Nations Children Fund, New York, 326 pp.

WHO - World Health Organization 2005b. Malaria control today, WHO, Geneva, 75 pp.

Zerba E 1988. Insecticidal activity of pyrethroids on insects of medical importance. Parasitol Today 4: S3-S7.

Zimmerman RH 1992. Ecology of malaria vectors in the Americas and future direction. Mem Inst Oswaldo Cruz 87: 371-383. 